\title{
Wilson's disease: assessment of D-penicillamine treatment
}

\author{
M VAN CAILLIE-BERTRAND, H J DEGENHART, I LUIJENDIJK, J BOUQUET, \\ AND M SINAASAPPEL
}

Department of Paediatrics, Erasmus University, University Hospital and Sophia Children's Hospital, Rotterdam, the Netherlands

SUMMARY Serum copper and zinc concentrations and 24 hour urinary copper and zinc excretion were determined serially from the beginning of treatment with D-penicillamine in four children with Wilson's disease. The data show a progressive decrease in both serum copper and zinc concentrations in all. Urinary copper excretion gradually levelled off to approximately $50 \%$ of initial values, but zinc excretion increased. Urinary zinc:copper ratios therefore increased with the duration of treatment. Copper elimination was considered adequate as soon as challenge with a test dose of D-penicillamine did not result in an increase in copper excretion. Urinary zinc excretion was increased further by the test dose. Zinc depletion was suspected clinically in one patient on D-penicillamine maintenance treatment. Lowering the dose alleviated the symptoms, urinary zinc loss decreased from 64 to $34 \mu \mathrm{mol} / 24$ hours, and copper excretion remained largely unchanged.

Data obtained indicate that D-penicillamine alters the metabolism of both copper and zinc. The extent of this is not only dose dependent but is also related to the efficacy of copper elimination. Both copper and zinc concentrations must by monitored to assess the benefits of treatment and the risks of inducing manifest or subclinical zinc deficiency.

The clinical manifestations of Wilson's disease are due to the accumulation of toxic amounts of copper in the liver, kidney, brain, cornea, and other tissues. Treatment with D-penicillamine (dimethylcysteine), combined with a low copper diet, first described by Walshe $^{1}$ and further confirmed by others ${ }^{2}$, has substantially improved the outcome of the disease. The ultimate prognosis, however, still depends on the age, symptoms, and degree of tissue damage at the time of diagnosis. ${ }^{34}$

D-penicillamine is an effective chelator of copper, is well absorbed from the gastrointestinal tract and promotes the urinary excretion of copper. ${ }^{1}$ Thus it allows the removal of the excessive amounts stored and prevents further accumulation of copper. According to current recommendations ${ }^{35}$ treatment should be continued for life and the dosage adapted to the patient's tolerance. Practical guidelines are few, however: a small dose may not be effective enough while a larger amount can be toxic. ${ }^{5}$ Other essential metals, especially zinc, may, by an increased dosage, be removed simultaneously. To assess the efficacy of treatment and avoid possible deficiency, we studied both zinc and copper values in serum and urine from the start of treatment with D-penicillamine in four children with the hepatic form of Wilson's disease.

\section{Patients and methods}

Patients. The four children were aged 5, 3, 7, and 10 years respectively when treatment was started. Criteria for diagnosis ${ }^{3}$ were (1) liver copper values greater than $325 \mu \mathrm{g} / \mathrm{g}$ dry weight, (2) urinary copper excretion greater than $1.26 \mu \mathrm{mol} / 24$ hours, (3) abnormal radiocopper kinetics in patients 1 and 2 (no substantial incorporation of ${ }^{64} \mathrm{Cu}$ in ceruloplasmin), (4) low serum ceruloplasmin values (less than $20 \mathrm{mg} / \mathrm{dl}$ ), and (5) familial occurrence in patients 2, 3, and 4. None had Kayser-Fleischer rings or neurologic symptoms. Patient 1 presented with a chronic, active hepatitis-like syndrome, patient 3 with liver fibrosis, and patients 2 and 4 were asymptomatic siblings of known patients with Wilson's disease. None was jaundiced. 
Zinc (

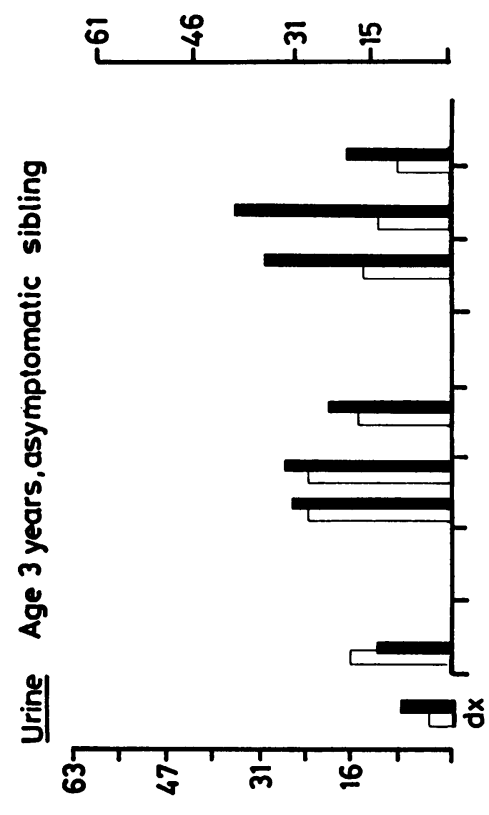

प७२ / lowr (口) Jəddos
Zinc (a) $\mu \mathrm{mol} / 24 \mathrm{~h}$

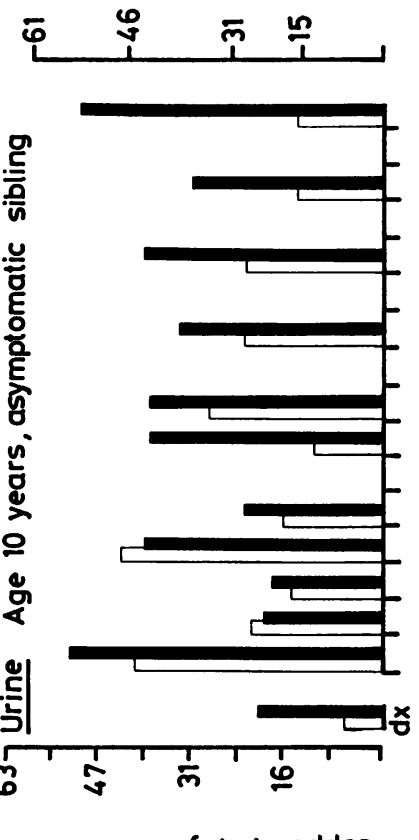

प७२। low $($ (a) دәddo

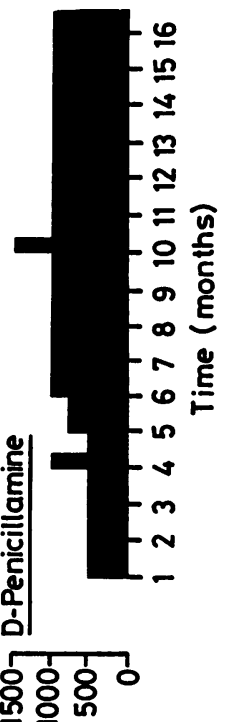

KDP/ bu
Zinc (a) $\mu \mathrm{mol} / 24 \mathrm{~h}$

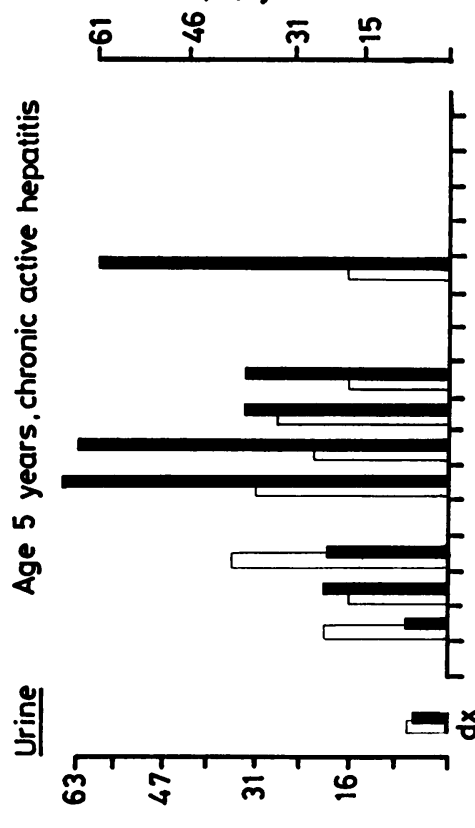

प७२ / lown (a) JaddoJ

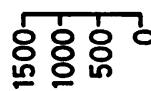

KDP/ $6 w$

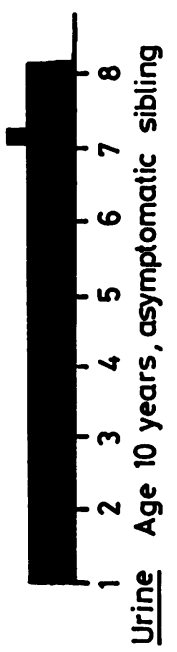

ஜํ$$
\text { पigriloun (a) doddo }
$$ 
Treatment. Soon after confirmation of the diagnosis of Wilson's disease the patients were treated with Dpenicillamine and a low copper diet was prescribed. The drug was given in three divided doses with meals. The initial dose was $500 \mathrm{mg}$ daily, except for patient 1 who received $300 \mathrm{mg}$. This dose was maintained during the first six months in patients 2 , 3 , and 4 , after which a challenge dose was given equal to the maintenance dose $+250 \mathrm{mg}$. Dependent upon the results obtained, the maintenance dose was increased or continued unchanged.

Methods. Liver function tests were carried out by standard methods. Serum and 24 hour urine samples for zinc and copper assays were collected in metal free containers at monthly intervals during the first year and at bimonthly intervals thereafter. All metal analyses were performed in duplicate by means of atomic absorption spectrophotometry.

\section{Results}

Clinical course. All children were asymptomatic with normal liver function tests at the last follow up. They did not develop any neurological signs of the disease or Kayser-Fleischer rings. Patient 1, however, who received $1 \mathrm{~g}$ D-penicillamine daily, developed skin lesions seven months after the start of treatment. These lesions consisted of alterations in hair texture with hair loss, parakeratosis of the hands and feet, and deep grooves on the soles of the feet. Urinary zinc excretion at that time was 64 $\mu \mathrm{mol} / 24$ hours. Reducing the dosage of Dpenicillamine to $750 \mathrm{mg}$ alleviated the symptoms, the 24 hour urinary zinc excretion decreased to 34 $\mu \mathrm{mol} / \mathrm{l}$, and the copper excretion remained largely unchanged at $19 \mu \mathrm{mol} / 24$ hours.

Copper and zinc data. Serum copper concentrations decreased steadily during treatment from $8 \cdot 0$ to $4 \cdot 4$, 8.7 to $3.1,11.4$ to 1.9 , and 10.1 to less than $1.5 \mu \mathrm{mol} / 1$ in patients $1,2,3$, and 4 respectively. Serum zinc concentrations, which were initially high (mean 27 $\mu \mathrm{mol} / \mathrm{l}$, range 38 to $22 \mu \mathrm{mol} / \mathrm{l}$ ) followed the same trend and reached the low normal range (mean 12.7 $\mu \mathrm{mol} / \mathrm{l}$, range 12 to $13.3 \mu \mathrm{mol} / \mathrm{l}$ ) during maintenance treatment. The lowest value $(9 \cdot 8 \mu \mathrm{mol} / \mathrm{l})$ was seen in patient 3,15 months after beginning treatment.

Urinary copper and zinc excretions are summarised in the Figure. With the exception of patient 4, copper excretion exceeded zinc excretion, even on a relatively low dose of D-penicillamine $(500 \mathrm{mg})$ at the start of treatment. As treatment continued the urinary copper excretion decreased progressively to approximately $50 \%$ of initial values, but the urinary zinc excretion increased further. Consequently the

\section{Bouquet, and Sinaasappel}

Table Twenty four hour urinary zinc copper ratios at the start of D-penicillamine (D-P) treatment and during treatment.

\begin{tabular}{|c|c|c|c|c|c|c|}
\hline \multirow{2}{*}{$\begin{array}{l}\text { Patient } \\
\text { No }\end{array}$} & \multicolumn{3}{|c|}{ Start of treatment } & \multicolumn{3}{|l|}{ Steady state } \\
\hline & & (No) & $\begin{array}{l}\text { After D-P } \\
\text { challenge }\end{array}$ & & $(\mathrm{No})$ & $\begin{array}{l}\text { After D-P } \\
\text { challenge }\end{array}$ \\
\hline 1 & 0.63 & (3) & - & $2 \cdot 18$ & (1) & $2 \cdot 88$ \\
\hline 2 & $1 \cdot 12$ & (4) & - & $2 \cdot 15$ & (2) & $3 \cdot 14$ \\
\hline 3 & $1 \cdot 01$ & (4) & 0.84 & $2 \cdot 33$ & (6) & $3 \cdot 64$ \\
\hline 4 & $1 \cdot 09$ & (3) & $0 \cdot 88$ & $2 \cdot 09$ & (16) & 3.76 \\
\hline mean $(+\mathrm{SD})$ & $0.98 \quad(0.4)$ & (14) & & $2 \cdot 17 \quad(0.6)$ & (25) & \\
\hline
\end{tabular}

urinary zinc copper ratios increased with the duration of treatment as shown in the Table.

At the end of the first phase of treatment (usually after more than six months) a challenge dose of Dpenicillamine resulted in a rise in zinc excretion. No further increase in copper excretion was then observed, suggesting that copper elimination was adequate. During the initial phase, however, this challenge dose did cause a rise in copper excretion as shown in patients 3 and 4 , four and five months respectively after the start of treatment.

\section{Discussion}

The data obtained show that D-penicillamine alters the excretion of both copper and zinc in patients with Wilson's disease. The extent of this is not only dose dependent but is also related to the efficacy of copper elimination. A comparison of the dissociation constants for metal-penicillamine complexes show a decreasing stability in the order $\mathrm{Hg}>$ $\mathrm{Cu}>\mathrm{Ag}>\mathrm{Pb}>\mathrm{Ni}>\mathrm{Cd}>\mathrm{Zn}>\mathrm{Co}>$ $\mathrm{Fe}>\mathrm{Mn} .^{8}$ Consequently more copper is excreted than zinc in the copper loaded patient at the beginning of treatment. As the mass of copper decreases, zinc having a lower affinity constant but being in relatively greater abundance will be excreted in greater amounts. Therefore, increased zincuria during D-penicillamine challenge is important both in assessing the benefits of treatment and the risks of inducing zinc as well as other trace metal deficiencies.

The effectiveness of treatment is usually assessed by serial determinations of transaminases, serum copper, and 24 hour urinary copper excretion. ${ }^{356}$ Our observations confirm previous reports (in children as well as in adults) that serum copper falls with time, as the non-ceruloplasmin bound fraction of serum copper returns to normal. ${ }^{17}$ Twenty four hour urinary excretion rises initially, but levels off to approximately $50 \%$ of the initial values $(9.5$ to 15 $\mu \mathrm{mol} / 24$ hours) during maintenance treatment. 
Serial serum zinc and 24 hour urinary zinc excretion, however, are not routinely measured. The Figure shows that these determinations give important complementary information for assessing the adequacy of treatment. If copper elimination has been effective, the increase in zinc excretion is not accompanied by any appreciable increase in copper excretion when the patient is challenged by a larger dose of D-pencillamine. If the challenge dose steps up copper excretion, however, a higher maintenance dose is indicated. This approach may help to improve the effectiveness and thus prevent partial failure of the treatment.

Because of its non-specificity as a chelator, Dpenicillamine may also affect other biologically important metals. Although in clinical use for more than 25 years, few data exist about its long term effects on the homeostasis of essential trace metals other than copper. ${ }^{9}$ Our findings support a previous report claiming the zinc deficiency may occur during treatment if urinary excretion exceeds the zinc absorption rate,$^{10}$ although this was not substantiated with balance studies. Some of the known side effects of the drug strongly suggest a zinc deficiency: skin lesions on pressure points, desquamations, psoriasis like eruptions, delayed wound healing, alopecia and sometimes loss of taste acuity, glossitis, and stomatitis. ${ }^{11}$ Some of the toxic effects may be attributable to hypersensitivity, others to the fact that D-penicillamine is an important antimetabolite of pyridoxine or to its direct action upon collagen. ${ }^{12} \mathrm{~A}$ few are almost certainly due to zinc deficiency and possibly also to deficiencies of other essential trace metals.
We thank Mrs Ingrid Bracke for secretarial help. We also thank Professor J Fernandes for reviewing the manuscript. This study was supported by the Sophia Foundation for Medical Research.

\section{References}

${ }^{1}$ Walshe JM. The discovery of the therapeutic use of D-penicillamine. J Rheumatol 1981;8(suppl 7):3-8.

2 Sternlieb I, Scheinberg IH. Prevention of Wilson's disease in asymptomatic patients. N Engl J Med 1968;278:352-9.

3 Alagille D, Odievre M. Wilson's disease. In: Liver and biliary tract disease in children. New York: John Wiley \& Sons, 1979:228-33.

4 Arima M, Takeshita K, Yoshino K, Kitahara T, Susuki Y. Prognosis of Wilson's disease in childhood. Eur $J$ Pediatr 1977;126:147-54.

${ }^{5}$ Landrieu P, Choulot JJ. Le traitement de la maladie de Wilson chez l'enfant. Arch Fr Pediatr 1976;33:665-75.

- Danks DM. Wilson's disease. In: Stanbury JB, Wijngaarden JB, Fredrickson DS, Goldstein JL, Brown MS, eds. The metabolic basis of inherited disease. New York: McGraw-Hill, 1983;1255-60.

7 Striekland GT, Frommer D, Lou M, et al. Wilson's disease in the United Kingdom and Taiwan. $Q J$ Med 1973;42:619-38.

${ }^{8}$ McCall JT, Goldstein NP, Randall RV, Gross JB. Comparative metabolism of copper and zinc in patients with Wilson's disease (hepatolenticular degeneration). Am J Med Sci 1967;254:35-45.

9 Crawhall JC. Penicillamine: twenty five years later. Ann Intern Med 1980;93:367-8.

${ }^{10}$ Klingberg WG, Prasad AS, Oberleas D. Zinc deficiency following penicillamine therapy. In: Prasad AS, ed. Trace elements in human health and disease: Vol 1 . New York: Academic Press, 1976:51-63.

"Greer KE, Askew FC, Richardson DR. Skin lesions induced by penicillamine. Arch Dermatol 1976;112:1267-9.

12 Halverson PB, Kozin F, Bernhard GC, Goldman AL. Toxicity of penicillamine. JAMA 1978;240:1870-1.

Correspondence to Dr H J Degenhart, Sophia Children's Hospital, Gordelweg 160,3038 GE, Rotterdam, the Netherlands.

Received 4 February 1985 